\title{
Knowledge of students from a health sciences university on human error and patient safety
}

\author{
Iohanna A. Paiva*1, Bruna M.B.L. Brasil ${ }^{1}$, Naiana P. Alves ${ }^{1}$, Káren M.B. Nascimento ${ }^{2}$, George J.B. Sousa ${ }^{1}$, Maria \\ Lúcia D. Pereira ${ }^{1}$, Rhanna E.F.L. Carvalho ${ }^{1}$ \\ ${ }^{1}$ Health Sciences Centre, Ceara State University, Fortaleza, Brazil \\ ${ }^{2}$ General Hospital of Fortaleza, Fortaleza, Brazil
}

Received: October 5, 2020

Accepted: May 27, 2021

Online Published: June 10, 2021

DOI: $10.5430 /$ jnep.v11n10p26

URL: https://doi.org/10.5430/jnep.v11n10p26

\begin{abstract}
Objective: This research aimed to identify the knowledge of students from a health science university on human error and patient safety.

Methods: This is an observational, cross-sectional research with a quantitative approach. A total of 228 students of the following baccalaureate courses participated: Physical Education, Nursing, Medicine, Nutrition, and Psychology. The study was conducted in the second semester of 2019 through an online questionnaire with 27 closed and 4 open questions. Simple frequencies, central tendency measures, and correlation tests were used to analyze the data. The IRAMUTEQ software was used to analyze the answers to open questions.

Results: The study demonstrated that the Nursing students had more contact with the patient safety theme and greater confidence to perform techniques during clinical practice. In general, students pointed out positive responses regarding knowledge about patient safety, such as: recognition of the possibility of errors, the importance of communication, and learning from mistakes. Conclusion: The results may contribute to strengthening teaching about patient safety in universities.
\end{abstract}

Key Words: Patient safety, Continuing education, Health education

\section{INTRODUCTION}

The repercussion of errors in health care has raised important discussions about patient safety and the search for solutions to achieve a high quality of healthcare.

Patient safety is a movement that has risen since the publication of the report: "To Err Is Human: Building a Safer Health System" in 1999, issued by the Institute of Medicine (IOM) of the United States of America. This report revealed that health care in that country was not as safe as it should be, since at least 44 to 98,000 Americans died in hospitals because of errors that could have been avoided. ${ }^{[1]}$
One of the answers to this problem was the creation of the World Alliance for Patient Safety, in 2004, by the World Health Organization (WHO). The alliance was created in a collaboration between the WHO and several member countries in order to raise awareness and political commitment to improve health care, supporting countries in the development of public policies and patient safety practices. ${ }^{[2]}$

According to the $\mathrm{WHO},{ }^{[3]}$ patient safety is the reduction of risk of unnecessary harm associated with health care to an acceptable minimum. An acceptable minimum refers to the collective notions of given current knowledge, resources

*Correspondence: Iohanna A. Paiva; Email: iohanna.aragao@gmail.com; Address: Health Science Centre, Ceara State University, Fortaleza, Brazil. 
available, and the context in which care is delivered. In addition, a patient safety incident is any unplanned or unintended event or circumstance which could have resulted or did result in harm to a patient. ${ }^{[3]}$

Given the complexity of care, health professionals are susceptible to errors. When a health professional makes an error that generates harm to a patient, this is defined as an adverse event. $^{[3]}$

Errors in health care are associated with several institutional, financial, structural, and human factors, which can be related to lack of knowledge and skills. ${ }^{[4]}$ Training institutions and universities have an elementary role in governing the knowledge and skills of professionals in the health field.

Contributing to educational institutions, the WHO developed the guide: "Patient Safety Curriculum Guide: Multiprofessional Edition", leading a global initiative with the aim of supporting schools and improving the education of these professionals regarding patient safety, aiming at providing a future workforce capable of exercising patient-centered care based on a culture of safety. ${ }^{[5]}$

In Brazil, the Ministry of Health and the National Health Surveillance Agency (Anvisa) in line with the WHO's global initiatives launched the National Patient Safety Program, with the objective of promoting strategies aimed at the prevention and reduction of risks associated with healthcare. Among the strategies covered by this program is the inclusion of patient safety in the curricula of health training institutions. ${ }^{[6]}$

According to Gonçalves, Siqueira and Caliri, ${ }^{[7]}$ the approach to the patient safety theme during academic training may reflect improvements in the quality of care provided by professionals in the health field. In addition, investigations about baccalaureate health students' knowledge and behaviors about patient safety can provide a baseline for patient safety curricula. ${ }^{[8]}$

This study aimed to identify the knowledge of students from a health sciences university on human error and patient safety.

\section{MeTHODS}

This is an observational, cross-sectional research with a quantitative approach. The study was carried out in the second semester of 2019 in a public health science university located in Northeastern Brazil.

The study population consisted of 593 undergraduate students regularly enrolled in the following courses: Physical Education, Nursing, Medicine, Nutrition, and Psychology. Students who had already completed at least one internship

Published by Sciedu Press in theoretical-practical disciplines were considered eligible. This criterion was considered as it would be necessary to answer the questionnaire.

The sample was stratified by course and sample size. The following parameters were considered: $\mathrm{Z}=1.96, p$-value $=.5$, sample error and significance level $=0.05 .{ }^{[9]}$ The minimum sample would be 141 students distributed as follows: Physical Education (32), Nursing (36), Medicine (43), Nutrition (14), and Psychology (16). However, 228 students answered the questionnaire.

Inclusion criteria were as follows: students regularly enrolled in one of the target courses who attended to at least one theoretical-practical internship class. In the target courses, this profile can be found in the middle stage of the courses. The exclusion criterion was the incomplete filling of the questionnaire.

The sample was recruited by convenience. Students were invited to participate in the research via social networks (WhatsApp and Instagram), by e-mail, and in person. A link to access the questionnaire was sent to all invited students.

The data collection instrument was adapted from a questionnaire developed by Yoshikawa et al. (2013). ${ }^{[10]}$ The questionnaire was composed of three sections. The first consisted of variables related to student's characterization (gender, age, course, semester, participation in research groups, or courses in the patient safety field). The second section contained statements regarding attitudinal and conceptual aspects of human error and was measured using a Likert scale $(5=$ strongly agree, 4 = agree, $3=$ neutral, $2=$ disagree, $1=$ strongly disagree). In the third section, the researchers created open questions as follows: "What is patient safety in your own words?", "What do you think hinders or prevents health professionals from developing assistance with less risk to the patient?", and "Do you have any suggestions on how to approach Patient Safety in undergraduate education?"

The questionnaire was applied through Google Forms platform. By accessing the link, participants initially were presented to a brief description of the research, followed by the Informed Consent (IC). After reading and declaring acceptance of the IC, the questionnaire was made available. Answers were automatically sent to the researcher to be inserted into the project database and subsequent statistical analysis.

The collected data were grouped and tabulated in an Excel spreadsheet and then transferred to the R software. The quantitative analysis comprised simple frequency calculations, central tendency measures, and the chi-square correlation test. A $p<.005$ was considered statistically significant. The an- 
swers to open questions were processed by the IRAMUTEQ software and analyzed by the Descending Hierarchical Classification (DHC).

IRAMUTEQ (Interface de R pour les Analyses Multidimensionnelles de Textes et de Questionnaires) is a software program created by Pierre Ratinaud based on software $\mathrm{R}$ which enables different types of textual data analysis and presents graphical representations derived from the lexicographic analysis. ${ }^{[1-14]}$ It began to be used in Brazil for qualitative data processing in 2013. ${ }^{[14]}$ The program identifies and reformats the text units, transforming Initial Context Units (UCI) into Elementary Context Units (ECU). The DHC is one of the analysis methods provided by IRAMUTEQ which aims to obtain classes of ECU that present similarities in the vocabularies and vocabulary different from the ECU of the other classes. In a set of open questions, each answer will be a text unit and the text segments are the contexts of the words. ${ }^{[13,14]}$

The study protocol was submitted and approved by the Institutional Review Board of the University in which the study was undertaken. The information provided by the participants was analyzed only by the researchers and codes were used to preserve the participants' identities.

\section{RESULTS}

A total of 228 students from five baccalaureate health courses participated in the research. From this sample, 151 (66.2\%) were female, $146(64 \%)$ were 21 to 24 years old, with a minimum age of 19 and a maximum age of 52 years. Nursing students $(76 ; 33.3 \%)$ in the last stage of the course $(68$; $29.8 \%$ ) were the ones who returned more questionnaires (see Table 1).

From the total sample, $182(79.8 \%)$ students reported participation in research group meetings and, from these, 146 $(70.2 \%)$ reported that the patient safety theme has never been discussed in the groups' discussions. Physical education and Psychology students (85\% and 95\%, respectively) reported that the subject of Patient Safety is not addressed in their courses.

A total of $141(61.2 \%)$ students reported prior participation in lectures or workshops about Patient Safety and most of them were Nursing students $(71,93.4 \%$ ) (see Table 2).

Proportions of students in all courses reported that they have previously attended to classes about Patient Safety, but the proportion of students that answered negatively to this question was higher in the Physical education and Psychology groups. The Nursing students were the ones that had more contact with the patient safety theme $(64,84.2 \%)$ (see Table

\section{2).}

Table 1. Demographic characteristics of the students $(n=$ 228)

\begin{tabular}{|c|c|c|}
\hline Variables & $\mathbf{n}$ & $\mathbf{F}$ \\
\hline \multicolumn{3}{|l|}{ Gender } \\
\hline Female & 151 & 66.2 \\
\hline Male & 77 & 33.8 \\
\hline \multicolumn{3}{|l|}{ Age } \\
\hline $19 \mathrm{I}-21$ & 30 & 13.1 \\
\hline $21 \mathrm{I}-23$ & 84 & 36.8 \\
\hline $23 \mathrm{I}-25$ & 62 & 27.2 \\
\hline $25 \mathrm{I}-27$ & 24 & 10.5 \\
\hline$\geq 27$ & 28 & 12.1 \\
\hline \multicolumn{3}{|l|}{ Course } \\
\hline Nursing & 76 & 33.3 \\
\hline Medicine & 49 & 21.5 \\
\hline Physical Education & 45 & 19.7 \\
\hline Nutrition & 36 & 15.8 \\
\hline Psychology & 22 & 9.6 \\
\hline \multicolumn{3}{|l|}{ Semester in course* } \\
\hline 9th semester & 68 & 29.8 \\
\hline 7th semester & 47 & 20.6 \\
\hline 5th semester & 36 & 15.8 \\
\hline 8th semester & 23 & 10.1 \\
\hline 4th semester & 20 & 8.8 \\
\hline 6 th semester & 17 & 7.5 \\
\hline 10th semester & 11 & 4.8 \\
\hline 12 th semester & 3 & 1.3 \\
\hline 11 th semester & 3 & 1.3 \\
\hline \multicolumn{3}{|l|}{ University admission } \\
\hline Entrance exam & 196 & 86 \\
\hline ENEM National High School Leaving Exam & 32 & 14 \\
\hline
\end{tabular}

*In Brazil, undergraduate courses last between 4 and 6 years, and are divided in semesters.

When asked about feeling safe to perform techniques during clinical practice, $150(65.8 \%)$ students answered that they did not felt safe, with a statistically significant difference between the courses $(p<.005)$. Physical Education and Nursing students were more confident when compared to the other students.

When asked about having made an error that caused harm to a patient, $217(95.2 \%)$ students answered that they did not, however, $111(48.7 \%)$ reported that they had already made some mistake, but no harm was done. A total of $121(53.1 \%)$ students considered that supervision by healthcare professionals during clinical practice was adequate. A significant difference between the courses was also found in regard to this question and Physical education students achieved best 
results (see Table 3 ).

In general, answers to the 13 items of the questionnaire about students' knowledge of patient safety were positive (see Table 4).

Table 2. Students' participation in research group meetings, courses, and classes on patient safety

\begin{tabular}{|c|c|c|c|c|c|c|c|c|c|c|c|c|c|}
\hline & & \multicolumn{12}{|c|}{ Course } \\
\hline & & \multicolumn{2}{|c|}{$\begin{array}{l}\text { Physical } \\
\text { education }\end{array}$} & \multicolumn{2}{|c|}{ Nursing } & \multicolumn{2}{|c|}{ Medicine } & \multicolumn{2}{|c|}{ Nutrition } & \multicolumn{2}{|c|}{ Psychology } & \multicolumn{2}{|c|}{ Total } \\
\hline & & $\mathbf{n}$ & $\%$ & $\mathbf{n}$ & $\%$ & $\mathbf{n}$ & $\%$ & $\mathbf{n}$ & $\%$ & $\mathbf{n}$ & $\%$ & $\mathbf{N}$ & $\%$ \\
\hline \multirow{2}{*}{$\begin{array}{l}\text { Do you participate in any } \\
\text { research group in your } \\
\text { university? }\end{array}$} & Yes & 26 & 57.8 & 69 & 90.8 & 47 & 95.9 & 27 & 75.0 & 13 & 59.1 & 182 & 79.8 \\
\hline & No & 19 & 42.2 & 7 & 9.2 & 2 & 4.1 & 9 & 25.0 & 9 & 40.9 & 46 & 20.2 \\
\hline \multirow{2}{*}{$\begin{array}{l}\text { If you participate in a } \\
\text { research group, is patient } \\
\text { safety addressed in the } \\
\text { group meetings? }\end{array}$} & Yes & 5 & 14.3 & 37 & 49.3 & 11 & 22.9 & 8 & 26.7 & 3 & 5.0 & 62 & 29.8 \\
\hline & No & 30 & 85.7 & 38 & 50.7 & 37 & 77.1 & 22 & 73.3 & 19 & 95.0 & 146 & 70.2 \\
\hline \multirow{2}{*}{$\begin{array}{l}\text { Have you ever attended to a } \\
\text { class in your undergraduate } \\
\text { course about the patient } \\
\text { safety theme? }\end{array}$} & Yes & 19 & 42.2 & 71 & 93.4 & 29 & 59.2 & 13 & 36.1 & 9 & 40.9 & 141 & 61.8 \\
\hline & No & 26 & 57.8 & 5 & 6.6 & 20 & 40.8 & 23 & 63.9 & 13 & 59.1 & 87 & 38.2 \\
\hline \multirow{2}{*}{$\begin{array}{l}\text { Have you ever participated } \\
\text { in a course or attended to a } \\
\text { lecture about patient safety? }\end{array}$} & Yes & 10 & 22.2 & 64 & 84.2 & 19 & 38.8 & 12 & 33.3 & 1 & 4.5 & 106 & 46.5 \\
\hline & No & 35 & 77.8 & 12 & 15.8 & 30 & 61.2 & 24 & 66.7 & 21 & 95.5 & 122 & 53.5 \\
\hline
\end{tabular}

Table 3. Students' answers to questions about the occurrence of errors

\begin{tabular}{|c|c|c|c|c|c|c|c|c|c|c|c|c|c|c|}
\hline & & \multicolumn{13}{|c|}{ Course } \\
\hline & & \multicolumn{2}{|c|}{$\begin{array}{l}\text { Physical } \\
\text { education }\end{array}$} & \multicolumn{2}{|c|}{ Nursing } & \multicolumn{2}{|c|}{ Medicine } & \multicolumn{2}{|c|}{ Nutrition } & \multicolumn{2}{|c|}{ Psychology } & \multicolumn{3}{|c|}{ Total } \\
\hline & & $\mathbf{n}$ & $\%$ & $\mathbf{n}$ & $\%$ & $\mathbf{n}$ & $\%$ & $\mathbf{n}$ & $\%$ & $\mathbf{n}$ & $\%$ & $\mathbf{n}$ & $\%$ & $p$ \\
\hline \multirow{2}{*}{$\begin{array}{l}\text { Do you feel safe } \\
\text { during clinical } \\
\text { practice to perform } \\
\text { techniques you } \\
\text { learned in your } \\
\text { training without } \\
\text { making mistakes? }\end{array}$} & Yes & 20 & 44.4 & 34 & 44.7 & 13 & 26.5 & 7 & 19.4 & 4 & 18.2 & 78 & 34.2 & \multirow{2}{*}{$.01^{*}$} \\
\hline & No & 25 & 55.6 & 42 & 55.3 & 36 & 73.5 & 29 & 80.6 & 18 & 81.8 & 150 & 65.8 & \\
\hline \multirow{2}{*}{$\begin{array}{l}\text { Have you ever } \\
\text { made a mistake } \\
\text { that caused harm } \\
\text { to the patient? }\end{array}$} & Yes & 0 & 0 & 2 & 2.6 & 6 & 12.2 & 2 & 5.6 & 1 & 4.5 & 11 & 4.8 & \multirow{2}{*}{.06} \\
\hline & No & 45 & 100.0 & 74 & 97.4 & 43 & 87.8 & 34 & 94.4 & 21 & 95.5 & 217 & 95.2 & \\
\hline \multirow{2}{*}{$\begin{array}{l}\text { Have you ever } \\
\text { made a mistake } \\
\text { with no harm to the } \\
\text { patient? }\end{array}$} & Yes & 15 & 33.3 & 37 & 48.7 & 27 & 55.1 & 18 & 50.0 & 14 & 63.6 & 111 & 48.7 & \multirow{2}{*}{.13} \\
\hline & No & 30 & 66.7 & 39 & 51.3 & 22 & 44.9 & 18 & 50.0 & 8 & 36.4 & 117 & 51.3 & \\
\hline \multirow{2}{*}{$\begin{array}{l}\text { Do you consider } \\
\text { that supervision } \\
\text { provided by } \\
\text { healthcare } \\
\text { professionals } \\
\text { during your } \\
\text { clinical practices } \\
\text { was adequate? }\end{array}$} & Yes & 33 & 73.3 & 39 & 51.3 & 22 & 44.9 & 17 & 47.2 & 10 & 45.5 & 121 & 53.1 & \multirow{2}{*}{$.04^{*}$} \\
\hline & No & 12 & 26.7 & 37 & 48.7 & 27 & 55.1 & 19 & 52.8 & 12 & 54.5 & 107 & 46.9 & \\
\hline
\end{tabular}


Table 4. Students' answers about patient safety and median scores

\begin{tabular}{|c|c|c|c|c|}
\hline Patient safety aspects & $\begin{array}{l}\text { SD and } D^{*} \\
\mathrm{~N}(\%)\end{array}$ & $\begin{array}{l}\text { Neutral } \\
\text { N (\%) }\end{array}$ & $\begin{array}{l}\text { A and SA* } \\
\mathrm{N}(\%)\end{array}$ & Median \\
\hline 1 - Health errors are inevitable. & 95 (41.7) & $12(5.3)$ & $121(53.1)$ & 4.0 \\
\hline 2 - Competent professionals do not make mistakes that cause harm to patients. & $143(62.7)$ & $19(8.3)$ & $66(29)$ & 2.0 \\
\hline $\begin{array}{l}3 \text { - When an error occurs, everyone involved (professionals, students, managers, and } \\
\text { patients) must discuss its causes. }\end{array}$ & $4(2.0)$ & $2(1.0)$ & $222(97.4)$ & 5.0 \\
\hline $\begin{array}{l}4 \text { - Working more carefully after an error has occurred, can be considered an effective } \\
\text { prevention strategy. }\end{array}$ & $12(5.3)$ & $10(4.4)$ & $206(90.3)$ & 5.0 \\
\hline 5 - A systemic analysis of facts should be used to implement error prevention measures. & $2(0.9)$ & $6(2.6)$ & $220(96.5)$ & 5.0 \\
\hline 6 - Preventive measures must always be taken after any damage is caused. & $34(14.9)$ & $6(3.0)$ & $188(82.5)$ & 5.0 \\
\hline $\begin{array}{l}7 \text { - Teachers must always be informed about the existence of conditions that can favor the } \\
\text { occurrence of errors in clinical practice settings. }\end{array}$ & $0(0.0)$ & $2(1.0)$ & $226(99.1)$ & 5.0 \\
\hline $\begin{array}{l}8 \text { - Students should always communicate the occurrence of errors to the teachers/supervisors } \\
\text { responsible for clinical practices. }\end{array}$ & $2(1.0)$ & $3(1.3)$ & $223(97.5)$ & 5.0 \\
\hline 9 - Students should always communicate the occurrence of errors to their colleagues. & $20(8.8)$ & $32(14)$ & $176(77.2)$ & 4.0 \\
\hline 10 - The patient and his family should always be informed about the occurrence of an error. & $30(13)$ & $38(16.7)$ & $160(70.2)$ & 4.0 \\
\hline $\begin{array}{l}11 \text { - If an error occurs but no harm is done to the patient, the need to communicate the } \\
\text { occurrence of such error to the patient and his family must be analyzed. }\end{array}$ & $56(24.5)$ & $37(16.2)$ & $135(59.2)$ & 4.0 \\
\hline $\begin{array}{l}12 \text { - After an error occurs, teachers must take corrective measures so that the student does not } \\
\text { make new mistakes. }\end{array}$ & $34(14.9)$ & $11(4.8)$ & $183(80.2)$ & 5.0 \\
\hline 13 - Systems for reporting the occurrence of errors can reduce future errors. & $3(1.3)$ & $8(3.5)$ & 217 (95.2) & 5.0 \\
\hline
\end{tabular}

Note. SD: strongly disagree; D: disagree; A: agree; SA: strongly agree.

Most students agreed or strongly agreed with the questionnaire's items, especially with item \#7 (Teachers must always be informed about the existence of conditions that can favor the occurrence of errors in clinical practice settings) and \#8 (Students should always communicate the occurrence of errors to the teachers/supervisors responsible for clinical practices), with $99.1 \%$ and $97.5 \%$ of agreement, respectively.

Item \#2 (Competent professionals do not make mistakes that cause harm to patients) was expected to generate a high disagreement, which was confirmed since 143 (62.7\%) students disagreed or strongly disagreed with this item. This result shows that students understand that there are strategies to avoid errors that cause harm to the patient, but that even competent professionals make mistakes.

The IRAMUTEQ corpus processing regarding the openended question \#1: "What is patient safety in your own words?" resulted in 227 initial context units (ICU) and 233 elementary context units (ECU) from which 154 (66.09\%) remained in the final stage of the analysis.

A dendogram constructed consisting of five word classes, with class 1 and class 5 corresponding to 24 and $26.6 \%$ of the answers, respectively. The resulting words characterizing the answers were condition, reduce, causing damage, minimize, and strategies.

The corpus processing of the open-ended question \#2: "What do you think hinders or prevents health professionals from developing assistance with less risk to the patient?" resulted in
$228 \mathrm{ICU}, 232 \mathrm{ECU}$, and $165(71.12 \%)$ remained in the final stage. The dendogram for this item presented four classes, with classes 2 and 3 accounting for $33.9 \%$ and $27.3 \%$ of the answers. The resulting four words characterizing the answers about barriers to patient safety were technique, structure, excessive load, and patient safety.

Regarding open-ended question \#3: "Do you have any suggestions on how to approach Patient Safety in undergraduate education?", a total of 167 ICU, 176 ECU, and 107 final units $(60.80 \%)$ were obtained. Four word classes emerged from the analysis, as follows, with frequencies ranging from $20.6 \%$ to $29 \%$ : lectures, workshops, and optional courses.

\section{Discussion}

This study aimed to assess health sciences students' knowledge about patient safety. A total of 228 Nursing, Medicine, Physical education, Nutrition, and Psychology students participated. The findings were similar to the results of other studies reporting a predominance of female students and people under 25 years old. ${ }^{[10,15]}$

In the first part of the questionnaire, it was evidenced that most students participated in research group meetings, however, more than $70 \%$ reported that patient safety is not discussed in these meetings. This finding shows that even with all attention given to patient safety, there is still a need to support debate on this topic, since proactive attitudes must be taken to promote safety. ${ }^{[16]}$ 
Some students affirmed that they do not feel safe performing course-related techniques during clinical practice, which is a weakness. The development of self-confidence and security to carry out techniques and procedures is essential for improving the quality of care, resulting in a better and safer care process. ${ }^{[17]}$ The findings evidence a need to reinforce this process, aiming at training professionals to act safely.

About half of the participants stated that they made mistakes that did not cause harm to patients, which is a way of showing that they are learning from their mistakes. Admitting the possibility of error and knowing that it has happened is the first step towards the prevention of errors. From this step forward, factors that caused the error can be understood and consequently new errors can be avoided. ${ }^{[18]}$

Most students reported that supervision provided during clinical practices was adequate. This is a crucial element to ensure safe care since students need guidance and monitoring in their training, but lack of adequate supervision is still a limitation found in clinical practice scenarios. ${ }^{[18]}$

In what concerns errors in health care, Reason (2000) affirms that errors are more frequently related to an accumulation of systemic factors than to the "perversity of human nature", i.e., errors are a result of several factors, and not only of human factors. It is also important to consider that human beings are fallible and, thus, errors are expected, even in the best organizations. ${ }^{[19]}$ This corroborates the students' views since most disagreed with the item "Competent professionals do not make mistakes that cause harm to patients".

Communicating errors is the best approach to prevent new errors. Errors must be recognized and analyzed in order to explore possible interventions for each situation or problem. ${ }^{[20]}$

Communication is an essential tool when it comes to patient safety, since effective communication creates a relationship of trust between the various parties involved in healthcare, from managers to patients and their families. Errors can be more easily exposed through the creation of such relationships, allowing institutions to better intervene, train, and promote patient safety. ${ }^{[21]}$ The study findings indicate that the participating students have good knowledge about the importance of communication for patient safety.

In the last part of the questionnaire, students were asked about what patient safety is, and the most used words correspond to the WHO's definition of patient safety, which is "the reduction of unnecessary harm associated with healthcare to an acceptable minimum". ${ }^{[3]}$

According to the $\mathrm{WHO},{ }^{[3]}$ factors associated with healthcare errors are divided in three categories: human factors, system

Published by Sciedu Press factors, and external factors. Human factors are related to behaviors, performance, or communication at individual and team levels; system factors include the work environment and the organization's concern for patient safety; and external factors are those beyond the control of the organization such as the natural environment and legislative policies. In this context, it is seen that the factors reported by the participants are consistent with the factors defined by the WHO, and all factor mentioned by them fit at least one of these three categories.

Students also gave suggestions regarding the incorporation of patient safety into undergraduate education and practices, which corroborate with the WHO 2011 Patient Safety Curriculum Guide. According to this document, the integration of patient safety into theoretical-practical courses and simulations allows students to improve critical thinking towards patient safety issues and students can be better prepared to intervene correctly when they encounter patient safety threats. ${ }^{[5]}$

Finally, the analysis of the participants' answers showed that, in general, students have good knowledge on the subject of patient safety, as their responses are consistent with the literature and their suggestions can be applied to healthcare services' routine.

As limitations, the study employed a cross-sectional approach, was developed in only one university, and used a convenience sampling approach, which limits its generalizability. Thus, it is recommended that further research be replicated in other countries or regions to investigate how patient safety is being taught and learned in healthcare universities around the world.

The research findings stimulate the discussion of patient safety and healthcare errors between undergraduate students and teachers, including topics such as human fallibility, what to do to prevent adverse events, and what to do in the event of an error. Such topics should be discussed in the classroom to strengthen the culture of safety in healthcare institutions and to change the current "culture of guilt" that is so strongly ingrained in professionals' minds.

\section{Conclusion}

In conclusion, this study has found that nursing students have more contact with the patient safety theme during undergraduate education than students from other healthcare disciplines. With regard to errors during the clinical practice sessions, students mostly claim not to have made such errors, and a minority reported that they had happened but no harm was caused to patients. Moreover, the study revealed positive responses regarding the students' knowledge about 
patient safety, such as recognition of the possibility of errors and learning from mistakes, awareness of the importance of developing strategies to prevent errors, and recognition of the importance of communication between those involved in healthcare assistance allowing a collective and systemic reflection about healthcare related errors.

It is recommended the implementation of regularly scheduled simulation in nursing labs addressing real healthcare settings and situations with focus on themes related to the six international patient safety goals. Realistic simulation should be an educational strategy to students develop critical thinking about patient safety and learn to identify patient safety incidents. This research can contribute to the strengthening of the culture of safety in healthcare universities, and can raise important reflections by students, teachers, directors, and other members of educational institutions. Such reflections and discussions can be used in the development of projects to improve and strengthen patient safety in academic healthcare settings with implications to clinical practice.

\section{CONFliCtS OF INTEREST Disclosure}

The authors declare that there is no conflict of interest.

\section{REFERENCES}

[1] Kohn LT, Corrigan JM, Donaldson MS. To err is human: building a safer health system. United States: Institute of Medicine; 1999.

[2] World Health Organization. World Alliance for Patient Safety Forward Programme [Internet]. 2004 [cited 2020 Sep 29]. Available from: https://www.who.int/patientsafety/en/brochure final.pdf

[3] World Health Organization. The Conceptual Framework for the International Classification for Patient Safety [Internet]. 2009 [cited 2020 Sep 29]. Available from: https ://www . who.int/patientsafet y/taxonomy/icps_full_report.pdf

[4] Pereira FGF, Caetano JA. Human error and patient safety in health services. Rev enferm UFPI. [Internet]. 2014 [cited 2020 Sep 29]; 3(3): 15-119. Available from: https://ojs.ufpi.br/index.php/re ufpi/article/viewFile/1988/pdf https://doi.org/10.2 6694/reufpi.v3i3.1988

[5] World Health Organization. Patient safety curriculum guide: multiprofessional edition. Geneva: WHO; 2011.

[6] Brazilian Ministry of Health. Ordinance No. 529 - Institutes the National Patient Safety Program (PNSP). Official Diary of the Brazilian Union. 2013 Apr 1; 43.

[7] Gonçalves N, Siqueira LDC, Caliri MH. Teaching patient safety in undergraduate courses: a bibliometric stud. Rev enferm UERJ. 2017; 25. https://doi.org/10.12957/reuerj . 2017.15460

[8] Murray M, Sundin D, Cope V. New graduate registered nurses' knowledge of patient safety and practice: A literature review. J Clin Nurs. 2018; 27: 31-47. PMid:28252838 https://doi.org/10.1111/ jocn. 13785

[9] Vieira S. Introdução a bioestatistica. 4th ed. Rio de Janeiro: Elsevier; 2011.

[10] Yoshikawa JM, Sousa BEC, Peterlini MAS, et al. Comprehension of undergraduate students in nursing and medicine on patient safety. Acta Paul Enferm. 2013; 26(1): 21-29. https ://doi .org/10.159 0/S0103-21002013000100005

[11] Kami MTM, Larocca LM, Chaves MMN, Lowen IMV, Souza VMP, Goto DYN. Working in the street clinic: use of IRAMUTEQ software on the support of qualitative research. Esc Anna Nery [Internet]. 2016 [cited 2016 Nov 20]; 20(3): e20160069. Available from: http://www.scielo.br/pdf/ean/v20n3/en_1414-814 5-ean-20-03-20160069.pdf

[12] Ratinaud P. IRAMUTEQ: Interface de R pour les Analyses Multidimensionnelles de Textes et de Questionnaires [Computer software]. 2009 [citado 2015 mar 20].

[13] Camargo BV, Justo AM. Tutorial para uso do software de análise textual IRAMUTEQ. Universidade Federal de Santa Catarina [Internet]. 2013 [citado 2015 out 15]. Available from: http: //www . iramuteq .org/documentation/fichiers/tutoriel-en-portugais

[14] Camargo BV, Justo AM. IRAMUTEQ: um software gratuito para análise de dados textuais. Temas Psicol [Internet]. 2013 [citado 2015 out. 15]; 21(2): 513-8. https ://doi .org/10.9788/TP2013.2-1 6

[15] Cauduro GMR, Magnago TSBS, Andolhe R, et al. Patient safety in the understanding of health care students. Rev Gauch Enferm. 2017; $38(2)$.

[16] Araújo MAN, Filho WDL, Silveira RS, et al. Patient safety in the perspective of nurses: A multi professional issue. Enferm Foco. 2017; 8(1): 52-56. https://doi.org/10.21675/2357-707X.2017.v 8.n1. 984

[17] Meska MHG, Mazzo A, Jorge BM, et al. Urinary retention: Implications of low-fidelity simulation training on the self-confidence of nurses. Rev Esc Enferm USP. 2016; 50(5): 833-839. PMid:27982403 https://doi.org/10.1590/s0080-623420160000600017

[18] Wegner W, Silva SC, Kantorski KJC, et al. Education for culture of patient safety: Implications to professional training. Esc Anna Nery Rev Enferm. 2016; 20(3). https ://doi.org/10.5935/1414-8 145. 20160068

[19] Reason J. Human error: models and management. BMJ. 2000; 320:768-70. PMid:10720363 https://doi.org/10.1136/bmj . 320.7237 .768

[20] Batista J, Cruz EDA, Alpendre FT, et al. Safety culture and communication about surgical errors from the perspective of the health team Rev Gauch Enferm. 2019; 40. PMid:30652804 https : //doi.org/ 10.1590/1983-1447.2019.20180192

[21] Nogueira JWS, Rodrigues MCS. Effective communication strategies for managing disruptive behaviors and promoting patient safety. Cogitare Enferm. 2015; 20(3): 636-640. https ://doi.org/10.5380/ ce.v20i3.40016 